\title{
The beginning of a seed: regulatory mechanisms of double fertilization
}

\author{
Andrea Bleckmann ${ }^{1}$, Svenja Alter ${ }^{2}$ and Thomas Dresselhaus ${ }^{1 *}$ \\ ' Cell Biology and Plant Biochemistry, Biochemie-Zentrum Regensburg, University of Regensburg, Regensburg, Germany \\ 2 Plant Breeding, Center of Life and Food Sciences Weihenstephan, Technische Universität München, Freising, Germany
}

\section{Edited by:}

Paolo Sabelli, University of Arizona, USA

\section{Reviewed by:}

Yanhai Yin, lowa State University, USA

Meng-Xiang Sun, Wuhan University, China

*Correspondence:

Thomas Dresselhaus, Cell Biology and Plant Biochemistry,

Biochemie-Zentrum Regensburg,

University of Regensburg,

Universitätsstrasse 18, 93053

Regensburg, Germany

e-mail: thomas.dresselhaus@ur.de
The launch of seed development in flowering plants (angiosperms) is initiated by the process of double fertilization: two male gametes (sperm cells) fuse with two female gametes (egg and central cell) to form the precursor cells of the two major seed components, the embryo and endosperm, respectively. The immobile sperm cells are delivered by the pollen tube toward the ovule harboring the female gametophyte by species-specific pollen tube guidance and attraction mechanisms. After pollen tube burst inside the female gametophyte, the two sperm cells fuse with the egg and central cell initiating seed development. The fertilized central cell forms the endosperm while the fertilized egg cell, the zygote, will form the actual embryo and suspensor. The latter structure connects the embryo with the sporophytic maternal tissues of the developing seed. The underlying mechanisms of double fertilization are tightly regulated to ensure delivery of functional sperm cells and the formation of both, a functional zygote and endosperm. In this review we will discuss the current state of knowledge about the processes of directed pollen tube growth and its communication with the synergid cells resulting in pollen tube burst, the interaction of the four gametes leading to cell fusion and finally discuss mechanisms how flowering plants prevent multiple sperm cell entry (polyspermy) to maximize their reproductive success.

Keywords: pollen tube, ovule, gamete interaction, cell fusion, signaling, fertilization, polyspermy

\section{INTRODUCTION}

High crop yield strongly depends on efficient formation of numerous ovules, which after successful fertilization, develop into seeds comprising seed coat, embryo, and endosperm. In angiosperms, the haploid gametophytic generations produce the male and female gametes required to execute double fertilization. Both gametophytes are reduced to only a few cells. The female gametophyte is deeply embedded and thus protected by the maternal sporophytic tissues of the pistil (Figure 1). It harbors the female gametes (egg and central cell) and is surrounded by the nucellus tissue as well as the inner and outer integuments. After fertilization these different tissues form the seed coat. The female gametophyte arises from a megaspore mother cell though processes known as megasporogenesis and megagametogenesis (for review see Evans and Grossniklaus, 2009; Drews and Koltunow, 2011). In $\sim 70 \%$ of all angiosperm species including Arabidopsis and maize the embryo sac develops according to the Polygonum type (Drews et al., 1998). The functional megaspore undergoes three mitotic divisions resulting in a syncytium containing eight nuclei. After nuclei migration and cellularization seven cells are differentiated: the haploid egg cell and its two adjoining synergid cells are located at the micropylar pole forming the egg apparatus. The homodiploid central cell containing two fused or attached nuclei is located more centrally, whereas three antipodal cells are found at the chalazal pole of the ovule opposite to the egg apparatus. While synergid cells are essential for pollen tube attraction, burst and sperm cell release (see below), the function of antipodal cells is so far unknown. During female gametophyte maturation antipodal cells are degenerating in the ovule of the eudicot model plant Arabidopsis (Mansfield et al., 1991), whereas they proliferate in other species including grasses and form a cluster of about 20-40 cells (Diboll and Larson, 1966).

The haploid male gametophyte (pollen grain) is formed during the processes of microsporogenesis and microgametogenesis from the microspore mother cell by meiosis and two successive mitotic divisions resulting in the formation of a tricellulate pollen grain. The vegetative cell encases the two sperm cells, which are connected with the vegetative cell nucleus by the generative cell plasma membrane, forming the male germ unit (MGU). MGU formation ensures the simultaneous delivery of both gametes to the ovule (for review see McCue et al., 2011). The major task of the vegetative cell is to deliver the sperm cells through the maternal tissues of the style and ovary to an unfertilized ovule. After pollen germination, the vegetative cell forms a tube and grows by tip-based-growth mechanism along papillae cells of the stigma into the style toward the transmitting tract. Inside the transmitting tract, pollen tubes are guided toward the ovules by mechanical and chemotactic cues involving numerous interactions with the sporophytic style tissues. In many eudicots pollen tubes exit the transmitting tract and grow along the septum, the funiculus and the outer integument 


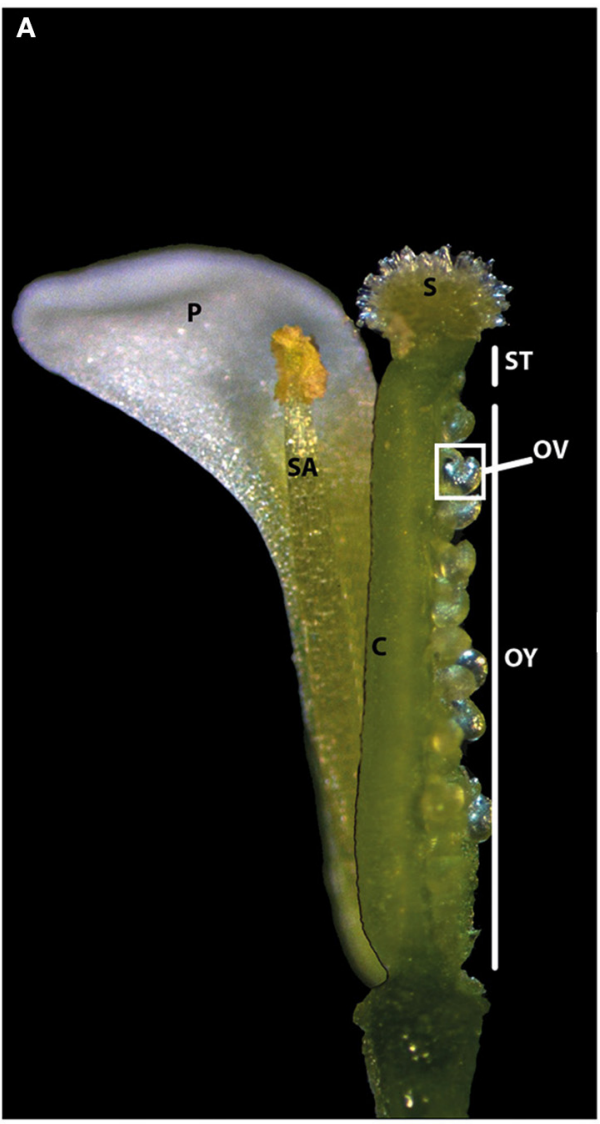

FIGURE 1 | The female gametophyte is deeply imbedded inside the female flower organs. (A) Dissected and reconstructed Arabidopsis flower. One of four petals (P) and one of six stamina (SA) are shown. They surround the pistil, which represents the female flower organ. It can be dissected into three parts. The upper part contains the papilla cells and forms the stigma (S), which is connected to the ovary (OY) by the style (ST). The ovary is formed by two fused carpels (C), which harbor two rows of ovules (OV). A side view (B) and front view (C) of a 3D-remodeled ovule reconstructed from toluidine blue stained single, successive ultra-thin sections of a dissected pistil. See Supplemental Movie 1 for whole series of sections. The ovule is connected to the septum (SE, yellow) containing the transmitting tract (TT, blue) by the funiculus ( $F$, petrol) and surrounded by the carpel tissue (C) (green). A 3D-model of a dissected ovule shown from various angles is shown in Supplemental Movie 2. The mature female gametophyte cells (FG) and the nucellus tissue (NC) are surrounded by the outer (OI) and inner integuments (II) (OI, blue; II, purple). The vacuole and nucleus of the different female gametophyte cells showed highest contrast and are therefore shown individually. Near to the micropyle (MY), the two nuclei of the two synergid cells (SY) are shown in red and green. The egg cell, indicated by EC in (D), has a comparably large vacuole (light blue) and its nucleus (blue) is located at its chalazal pole. The center of the female gametophyte is filled by the vacuole (light yellow) of the central cell, indicated by CC in (D), and its homo-diploid nucleus (yellow). The three degenerating antipodal cells, indicated by AP in turquoise color in (D) at the chalazal pole are not highlighted. (D) DIC microscopic image of a mature female gametophyte surrounded by the maternal sporophytic tissues of the ovule. The cell types and tissues are artificially colored as shown in (B,C). At full maturity the nucellus cell (NC) layer surrounding the developing embryo sac is flattened between inner integument (II) and female gametophyte cells. toward the micropyle of unfertilized ovules. In grasses the ovary contains a single ovule and the pollen tube is directly guided toward its surface after leaving the blind ending transmitting tract. The pollen tube continues to grow along its surface toward the micropylar region (for review see Lausser and Dresselhaus, 2010). Finally, the pollen tube enters the micropyle, an opening between the inner and outer integuments, and grows toward the two synergid cells. The pollen tube bursts and sperm cells are released. This process is associated with the degeneration of the receptive synergid cell due to programmed cell death. Subsequently, both sperm cells arrive at the gamete fusion site and fertilize the egg and central cell (Hamamura et al., 2011). From the moment of germination until sperm discharge the pollen grain/tube communicates with at least five different sporophytic and three different gametophytic cell types to successfully accomplish fertilization (Palanivelu and Tsukamoto, 2012). Its extended growth inside the female flower tissue is regulated by many different guidance, attraction and support mechanisms. After sperm cell release all gametes are activated, followed by fusion of their membranes and nuclei by processes known as plasmaand karyogamy, respectively. After successful double fertilization further signaling events are activated to prevent polyspermy. In this review we will summarize and discuss the cell-cell communication processes, which are essential to successfully accomplish double fertilization and to initiate seed development in angiosperms. 


\section{POLLEN TUBE GROWTH AND ATTRACTION POLLEN REJECTION}

Pollen tube growth and guidance toward the female gametes are controlled at various stages by chemotactic signals and growth support molecules derived from the sporophytic and gametophytic tissues of the female flower organs. Pollen grains placed on the stigma (Figure 1A) by contact, wind or different pollinators stick to the papilla cells and start to hydrate followed by their germination. The efficient adhesion of the pollen grain to the papilla cell is regulated by interaction events between these cells and may activate thereby inter- and intra-species barriers to prevent unsuccessful pollination and fertilization events already at this early time point during reproduction. Angiosperms possess different strategies to recognize self from alien pollen and evolved independent self-incompatibility (SI) mechanisms to prevent self-fertilization. Early SI mechanisms are based on cell-cell communication events between the papilla cells and the pollen grains, whereas later SI mechanisms occur while the growing pollen tube interacts with the cells of the transmitting tract. Species of the Solanaceae, for example, use a pistil-expressed SRNase, which penetrates the pollen tube (McClure et al., 1989; Luu et al., 2000). A compatible pollen tube expresses the Slocus F-box protein (SLF), which leads to the degradation of the S-RNase (Hua and Kao, 2006; Kubo et al., 2010), while in incompatible interactions intact S-RNase degrades RNAs resulting, for example, in the disruption of the actin cytoskeleton and other cellular processes (Liu et al., 2007; Roldán et al., 2012). In Papaveraceae SI depends on the small pistil secreted protein Papaver rhoeas style S (PrsS), which binds to the S-locus pollen tube membrane protein $P$. $r$. pollen $S(P r p S)$ and activates a $\mathrm{Ca}^{2+}$ dependent signaling cascade resulting in pollen inhibition and programmed cell death (Wheeler et al., 2009; Wu et al., 2011). SI is best understood in Brassicaceae, which use a surface-localized Slocus receptor kinase (SRK) in papilla cells (Takasaki et al., 2000) and a pollen coat localized cysteine-rich protein (SP11/SCR) (Schopfer, 1999; Shiba et al., 2001) to distinguish self from alien pollen. Their successful interaction leads to proteasome dependent degradation of Exo70A1, an essential component of the exocyst complex. It is thought to be involved in secretion of essential pollen germination factors necessary for pollen hydration (Synek et al., 2006; Samuel et al., 2009). Rejection of pollen in Brassicaceae thus occurs already during pollen hydration and germination at the surface of papilla cells. Little is known about SI in the economically important grasses (reviewed in Dresselhaus et al., 2011). Pollen hydration and germination appear not to be affected, although only grass pollen tubes are capable of penetrating the style and reach the transmitting tract. This indicates that SI in the grasses depends on successful interaction of the pollen tube with the sporophytic cells of the style and transmitting tract. The signaling events involved in this recognition process still await their discovery. More details about SI mechanisms can be found in Iwano and Takayama (2012), Watanabe et al. (2012) and Dresselhaus and Franklin-Tong (2013).

\section{POLLEN TUBE GUIDANCE TOWARD AND THROUGH THE TRANSMITTING TRACT}

After adhesion and hydration, compatible pollen germinates, penetrates the style and grows through the extracellular space of stylar cells toward the transmitting tract (Figure 1B). The growth direction of the pollen tube is regulated by the formation of different gradients including water, $\gamma$-amino butyric acid (GABA), calcium and other small molecules such as D-serine. The water flow during hydration forms an external gradient specifying the site of pollen tube outgrowth and was shown to be controlled by triacylglyceride (Lush et al., 1998; Wolters-Arts et al., 1998). $\mathrm{Ca}^{2+}$ influx into the pollen tube tip region is known to be essential for germination and tube growth (Brewbaker and Kwack, 1963; for a review see Steinhorst and Kudla, 2013a) and leads to the generation of an oscillating apex-based cytoplasmic $\mathrm{Ca}^{2+}$ $\left(\mathrm{Ca}_{\text {cyto }}^{2+}\right)$ gradient (Miller et al., 1992; Calder et al., 1997). Initially, papilla cells export $\mathrm{Ca}_{\text {cyto }}^{2+}$ by the auto-inhibited $\mathrm{Ca}^{2+}$-ATPase 13 (ACA13) at the pollen grain adhesion site (Iwano et al., 2004, 2014). Extracellular $\mathrm{Ca}^{2+}$ is then imported into the pollen tube by glutamate receptor-like channels (GLRs), which can be stimulated by D-serine (Michard et al., 2011). In animal systems it was shown that GLRs are non-selective cation channels catalyzing $\mathrm{Na}^{+}$and/or $\mathrm{Ca}^{2+}$ influx into cells. Binding of the agonist D-serine to GLRs should thus lead to channel opening resulting in a $\mathrm{Ca}_{\text {cyto }}^{2+}$ increase (Gilliham et al., 2006). D-serine is produced by Serine-Racemase1 (SR1), which shows an expression peak in the style indicating $\mathrm{D}$-serine availability. The induced changes in $\mathrm{Ca}_{\text {cyto }}^{2+}$ concentration in the pollen tube might thereafter regulate and coordinate many different signaling events like actin polymerization and thus influence pollen tube growth behavior and growth direction. $\mathrm{Ca}_{\text {cyto }}^{2+}$-sensors, belonging to the protein families of calmodulin (CaM), calmodulin-like proteins (CMLs), calcium-dependent protein kinases (CDPKs), and calcineurin Blike proteins (CBLs) are expressed in the pollen tube and are thought to control different cell-cell communication events indicated by their localization and overexpression phenotypes. The presence of these different $\mathrm{Ca}_{\text {cyto }}^{2+}$ receptors around the sperm cells and at the pollen tube tip indicate an essential role of $\mathrm{Ca}^{2+}$ signals both during pollen tube growth and double fertilization (Zhou et al., 2009; Steinhorst and Kudla, 2013b).

During pollen tube growth the tip needs to modulate the surrounding cell wall of stylar cells enabling its penetration through the extra-cellular space, most likely by interaction with extensinlike proteins and arabinogalactan proteins as well as the secretion of cell wall softening enzymes and inhibitors such as polygalacturonases and pectin methylesterase inhibitors (Cosgrove et al., 1997; Grobe et al., 1999; Stratford et al., 2001; Ogawa et al., 2009; Nguema-Ona et al., 2012; Woriedh et al., 2013). The transmitting tract is composed of small cylindrical cells that are surrounded by an extracellular matrix (ECM), which contains a mixture of glycoproteins, glycolipids, and polysaccharides (Lennon et al., 1998). The ECM provides essential nutrients as well as components for an accelerated, extended and guided pollen tube growth (Palanivelu and Preuss, 2006). Without an intact transmitting tract like in the NO TRANSMITTING TRACT (NTT) mutant or its target HALF FILLED (HAF), pollen tube growth is severely affected and either slowed down or prematurely terminated. NTT encodes a $\mathrm{C} 2 \mathrm{H} 2 / \mathrm{C} 2 \mathrm{HC}$ zinc finger transcription factor involved in ECM production and is essential for programmed cell death in the transmitting tract upon pollination (Crawford et al., 2007). $H A F$ encodes a bHLH transcription factor and is involved in NTT dependent transmitting tract regulation (Crawford and Yanofsky, 
2011). The transmitting tract-specific arabinogalactan glycoproteins TTS1 and TTS2 have a positive effect on in vitro grown tobacco pollen and show a gradient of increased glycosylation correlating with pollen tube growth direction inside the transmitting tract (Cheung et al., 1995; Wu et al., 1995). Another factor which has a positive effect on pollen tube growth and guidance is chemocyanin, a small secreted peptide in the style of lily (Kim et al., 2003). The different sporophyte-derived signals do not only guide or increase pollen tube growth rate, but rather lead to a change in the pollen transcriptome and thereby activate the pollen for female gametophyte-derived attraction signals (Higashiyama et al., 1998; Palanivelu and Preuss, 2006). Recently, de novo expression of closely related MYB transcription factors and other genes were reported to be induced during pollen tube growth through the style regulating themselves a number of downstream genes. Hence pollen tubes maturate during their growth through the sporophytic tissue and thereby become competent for fertilization (Leydon et al., 2013, 2014).

\section{OVULAR POLLEN TUBE GUIDANCE}

The signaling events that control pollen tube exit from the transmitting tract and guidance toward the ovule are not known. In Arabidopsis this process was shown to be tightly regulated and usually only a single pollen tube exits the transmitting tract in proximity of an unfertilized ovule. The pollen tube grows on the septum surface toward the funiculus, the tissue connecting the ovule with the septum (Figures 1B-D; Supplemental Movies $1,2)$. At the funiculus the pollen tube is directed through the micropyle inside the ovule by a mechanism known as micropylar guidance (Shimizu and Okada, 2000). In Arabidopsis a gradient of GABA was reported in front of the ovule. The transaminase POLLEN ON PISTIL2 (POP2) forms this gradient through GABA degradation. At moderate concentrations GABA stimulates pollen tube growth and thus likely supports growth toward the ovule (Palanivelu et al., 2003). Another candidate involved in micropylar guidance is D-serine, which was already described above. Its synthesizing enzyme gene $S R 1$ is also expressed in the ovule indicating the presence of D-serine (Michard et al., 2011). Semi-in vitro fertilization experiments revealed an oscillation of $\mathrm{Ca}_{\text {cyto }}^{2+}$ levels in growing pollen tubes depending on their distance from an unfertilized ovule and especially from the synergid cells (Shi et al., 2009; Iwano et al., 2012). The connection between $\mathrm{Ca}_{\text {cyto }}^{2+}$ and $\mathrm{D}$-serine by GLR channels in growing pollen tubes was already described above. The observed changes in the $\mathrm{Ca}_{\text {cyto }}^{2+}$ level depending on its distance from the synergid cells might again result from this interplay.

Recently, two pollen-expressed mitogen-activated protein kinases (MAPKs), MPK3 and MPK6, were identified in Arabidopsis, which are part of the ovular guidance network. In vivo pollination assays revealed that $m p k 3 / 6$ double mutant pollen tubes were not capable of growing along the funiculus after transmitting tract exit but micropylar guidance (see below) was not effected in the double mutants (Guan et al., 2014). MPK3/6 are two cytoplasmic protein kinases, which seem to be part of the signaling cascade mediating extracellular stimuli to changes in pollen tube growth direction.
In summary, our current understanding of ovular pollen tube guidance is very limited, but a whole orchestra of small molecules derived from the ovule seem to be involved in pollen tube growth support and attraction, and multiple signaling networks are required in pollen tubes to respond to the diverse set of signals and to direct their growth behavior.

\section{MICROPYLAR POLLEN TUBE GUIDANCE}

After arrival at the surface of the ovule, the pollen tube reaches the last phase of its journey, which is known as micropylar pollen tube guidance. It enters the micropyle, an opening between the two integuments, and directly grows toward the egg apparatus in species such as Arabidopsis (Figure 2A). In grasses the pollen tube first has to overcome a few layers of nucellus cells (Márton et al., 2005) before it also gets in contact with the filiform apparatus of the synergid cells, a thickened and elaborated cell wall at their micropylar pole, where the cell surface is extensively invaginated (Willemse and van Went, 1984; Huang and Russell, 1992). It was believed for a long time that the pollen tube grows through the filiform apparatus to enter one synergid cell, leading to pollen tube burst and cell death of the receptive synergid cell. Recently, it was shown that the pollen tube is repelled by the filiform apparatus and instead grows along the cell wall of the synergid cells until it reaches a certain point after the filiform apparatus where its growth is arrested and burst occurs explosively (Leshem et al., 2013). Pollen tube burst results in the discharge of its cytoplasmic contents including the two sperm cells. The synergid cells represent the main source for chemo-attractants required for micropylar pollen tube guidance. Moreover, laser ablation experiments in Torenia fournieri have demonstrated that a single synergid cell is sufficient and necessary to attract pollen tubes (Higashiyama et al., 2001). The major function of the filiform apparatus may thus be to considerably increase the micropylar surface of the synergid cells, which represent glandular cells of the egg apparatus. Many known components required for pollen tube growth and guidance are membrane-associated and accumulate at the filiform apparatus, which gives it the additional role of a signaling platform. It contains, for example, a high $\mathrm{Ca}^{2+}$ concentration, which is known to play a key role during the regulation of pollen tube growth (Brewbaker and Kwack, 1963; Chaubal and Reger, 1990; Iwano et al., 2004; Michard et al., 2011) and also seems to trigger pollen tube burst afterwards (see below). In Arabidopsis the formation of the filiform apparatus as well as the expression of different attractants in the synergid cells depend on the activity of the R2R3-type Myb transcription factor MYB98 (Kasahara et al., 2005; Punwani et al., 2007). Among other genes, MYB98 regulates the expression of genes encoding cysteine-rich proteins (CRPs), including those representing a subgroup of defensin-like (DEFL) polypeptides (Punwani et al., 2008; Takeuchi and Higashiyama, 2012).

In Torenia it was shown that a DEFL subgroup of CRPs called LUREs are secreted from the synergid cells and accumulate at the filiform apparatus (Okuda et al., 2009; Kanaoka et al., 2011). LUREs attract pollen tubes in a species-preferential manner from a distance of about $100-150 \mu \mathrm{m}$ and were recently shown to bind to the tip region of pollen tubes (Okuda et al., 2009, 2013). Due to their rapid molecular evolution it was difficult to 


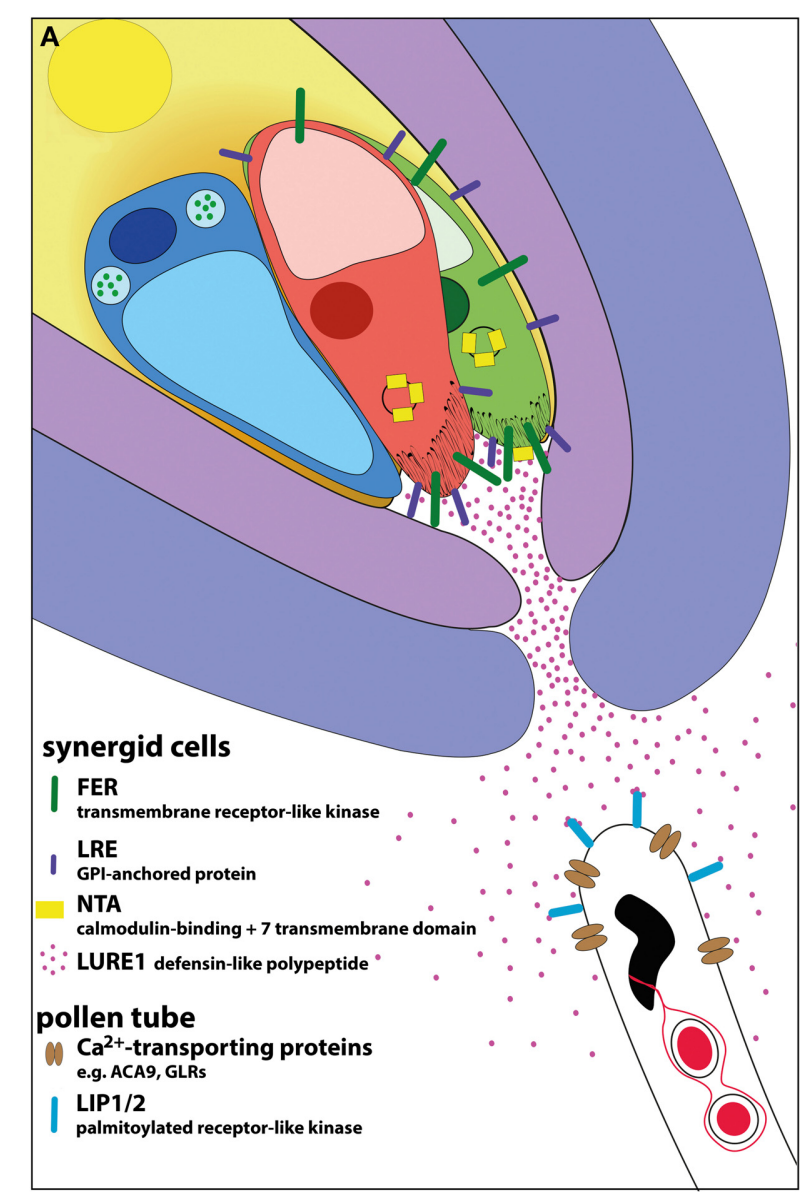

FIGURE 2 | Model of signaling events during micropylar pollen tube attraction and double fertilization in Arabidopsis. (A) The micropylar opening of the ovule is formed by the inner and outer integuments. The female gametophyte is "naked" at its micropylar pole containing one egg (colored in blue) and two synergid cells (colored in green and red) representing the egg apparatus. The central cell surrounds the egg apparatus. The synergid cells are the main sources of pollen tube attractants. Among other components, they secrete LURE peptides, which bind to pollen expressed LIP1/2 receptors thus directing pollen tube growth. Calcium transporters are involved in pollen tube growth control. The plasma membranes of synergid cells harbor a high concentration of receptors like FER and LRE, especially in the region of the filiform apparatus. Upon pollen tube perception NTA is relocated to the plasma membrane by FER activity likely regulated by $\mathrm{Ca}^{2+}$ oscillations inside the synergid cells. (B) The pollen

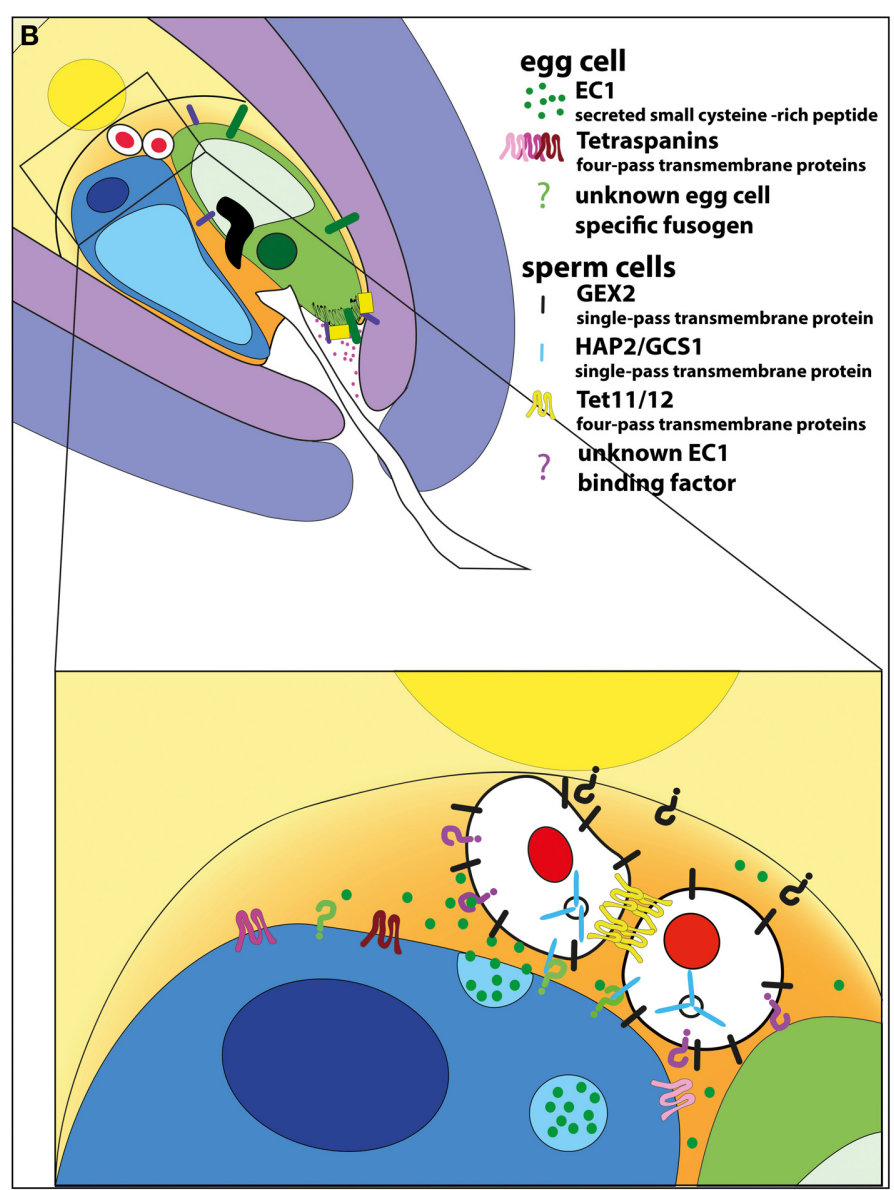

tube bursts when it reaches a certain point beyond the filiform apparatus and releases its cytoplasmic contents including the two sperm cells. Pollen tube burst depends on the presence and activation of FER-, LER-, NTA-, and VDD-dependent signaling cascades culminating in the death of the receptive synergid cell (indicated by diffusing red color). Released sperm cells are located at the gamete fusion side, between the two female gametes. The two sperm cells are connected to each other, likely involving tetraspanins. The male gametes adhere to female gametes by GEX2 located at their surface. After activation, the egg cell secrets EC1 leading to sperm cell activation and HAP2/GCS1 localization to the plasma membrane. HAP2/GCS1 and tetraspanins at the surface of gametes may be involved in mediating membrane fusion. Unknown egg and central cell-specific fusogenic proteins as well as EC1 receptor are indicated by question marks in green, black, and purple, respectively. identify orthologs in other plant species, but finally the DEFL subgroup CRP810/AtLURE1 of Arabidopsis was discovered to be involved in micropylar pollen tube guidance (Takeuchi and Higashiyama, 2012). In Zea mays, EGG APPARATUS1 (ZmEA1), a small hydrophobic precursor protein of 94 aa was reported as an egg apparatus-specific protein required for micropylar pollen tube guidance (Márton et al., 2005, 2012). ZmEA1 was shown to bind in a species-specific manner to the apical region of the pollen tube, where it is quickly internalized and degraded, likely keeping the pollen tube susceptible to pollen tube attractants while growing through the micropylar nucellus cell layers (Márton et al., 2012; Uebler et al., 2013).
More puzzling is the role of the central cell in micropylar guidance of the pollen tube. For example magatama (maa) mutants show defects in central cell maturation; both haploid nuclei are smaller and often fail to fuse. Pollen tubes grow in the direction of an unfertilized maa ovule but loose their way just before entering the micropyle. Moreover, mutant female gametophytes attracted two pollen tubes at a high frequency (Shimizu and Okada, 2000). MAA3 was recently shown to encode a helicase required for general RNA metabolism, which could explain the central cell maturation defect but not the defect in pollen tube guidance (Shimizu et al., 2008). Another example of central cell-dependent defects in micropylar pollen tube guidance is the 
transcriptional regulator CENTRAL CELL GUIDANCE (CCG), which is expressed exclusively in the central cell of the female gametophyte (Chen et al., 2007). These guidance defects may be indirect and caused by non-functional or immature central cells influencing maturation of egg apparatus cells and thus the generation of guidance components in these cells. It might also be possible that molecules generated by the MAA3 and CCG pathways directly regulate the generation of guidance molecules in the neighboring cells. Also the egg cell seems to be involved in micropylar guidance. GAMETE EXPRESSED 3 (GEX3) is a plasma membrane-localized protein, which is expressed in the unfertilized egg cell. Down-regulation of GEX3 by antisense RNA in the egg cell leads to defects in micropylar guidance by an unknown mechanism (Alandete-Saez et al., 2008).

Until recently, male factors and signaling pathways reacting to attractants secreted from the egg apparatus were unknown. The receptor-like kinases (RLKs) LOST IN POLLEN TUBE GUIDANCE1 (LIP1) and 2 (LIP2) have been identified, which are preferentially expressed in the pollen tube. Both proteins show membrane localization due to a palmitoylation site and are involved in the AtLURE1-dependent guidance mechanism. lip1/2 double mutant pollen reach the funiculus but fail to grow through the micropyle inside the ovule, and the pollen tube shows a reduced attraction toward AtLURE1 (Liu et al., 2013). However, it is unclear whether LIP $1 / 2$ are directly involved in LURE perception.

\section{POLLEN TUBE BURST AND SPERM CELL DISCHARGE}

Pollen tube burst seems to be regulated by RLKs located at surfaces of both male and female interaction partners (Figures 2A,B). The RLK FERONIA/SIRENE (FER/SRN) is expressed in most tissues including the synergid cells, where it localizes predominately at their surface in the filiform apparatus region. Loss-of-function mutants display a pollen tubeovergrowth phenotype. Pollen tube growth arrest and sperm cell discharge fail in fer ovules (Huck et al., 2003; Rotman et al., 2003; Escobar-Restrepo et al., 2007). FER acts as a cell surface regulator for RAC/ROP GTPases. Recently it was shown that FER binds to the small secreted peptide Rapid Alkalinization Factor (RALF), which leads to the inhibition of a plasma membrane $\mathrm{H}^{+}$-ATPase resulting in the suppression of cell elongation in the primary root (Haruta et al., 2014). Besides changes in the $\mathrm{pH}$, RALF also induces the increase of $\mathrm{Ca}_{\text {cyto }}^{2+}$ (Pearce et al., 2001; Haruta and Constabel, 2003; Haruta et al., 2008) and thus may influence pollen tube growth arrest and eventually its burst. The Arabidopsis genome contains around 30 RALF-like genes indicating the possibility that a pollen secreted RALF-like peptide may indeed be involved in FER-dependent pollen tube perception (Olsen et al., 2002). Other proteins were identified whose lossof-function resemble the fer phenotype such as the glycosylphosphatidylinositol (GPI)-anchored protein LORELEI (LRE) and the Mildew Resistance Locus O (MLO) family protein NORTIA (NTA). Both genes are expressed in synergid cells and show a similar pollen tube overgrowth phenotype (Capron et al., 2008; Kessler et al., 2010). NTA encodes a protein with multiple potential transmembrane domains as well as a calmodulin-binding site. The frequency of unfertilized ovules in lre/lre and nta/nta is less pronounced compared to fer/fer pistils. This finding indicates that FER activity is essential for pollen tube perception, while other, yet unknown factors act redundantly with LRE and NTA. These factors are all present at the synergid plasma membrane during pollen tube contact. However, while FER accumulates at the filiform apparatus already prior to pollen tube arrival, NTA relocalizes to the plasma membrane of the synergid cells at the filiform apparatus region upon pollen tube contact. In a transient expression system NTA is directly targeted to the plasma membrane. However, in Arabidopsis ovules under control of its endogenous promoter, NTA localizes to uncharacterized compartments within the cell, and becomes relocalized to the plasma membrane upon pollen tube arrival, indicating the presence of an active retention mechanism. This relocalization is FER-dependent and therefore connects FER to NTA in the same signaling network (Kessler et al., 2010). The presence of a calmodulin-binding domain in NTA supports the idea of a $\mathrm{Ca}^{2+}$-dependent signaling network, which is activated upon pollen tube arrival. Due to its predicted signal peptide and GPI anchor, LRE is expected to localize to the extracellular side of the plasma membrane after passage through the secretory pathway. But so far plasma membrane localization could only be shown in a transient expression system and not in synergid cells themselves (Capron et al., 2008). Whether LRE localization also changes during the process of fertilization needs to be elucidated. Another factor required for successful pollen tube/synergid cell communication is VERDANDI (VDD), a member of the plant-specific B3 superfamily of transcription factors. $V d d$ mutants show defects in antipodal and synergid cell identity and result in the lack of pollen tube burst after reaching the synergid cells. In contrast to fer, nta, or lre mutants, an overgrowth phenotype was not reported indicating that VDD may act downstream of cell surface signaling components (Matias-Hernandez et al., 2010). Little is known about male factors involved in pollen tube/synergid cell communication. Two closely related homologs of FER, ANXUR1 (ANX1), and ANX2 were reported to be involved in the timing of pollen tube burst or more precisely in the inhibition of pollen tube burst. In an in vitro pollen tube growth assay, pollen of double mutants show spontaneous discharge already after pollen bulge formation, whereas in vivo-grown pollen tubes germinate normally on a stigma but rupture in the style before arriving at the egg apparatus. Both receptors localize mainly to the apical tip of the pollen tube as well as in small vesicles (Boisson-Dernier et al., 2009; Miyazaki et al., 2009). Their over-expression inhibits growth by over-acting exocytosis and over-accumulation of secreted cell wall material (Boisson-Dernier et al., 2013) suggesting that the main function is associated with coordination of growth through the style rather than sperm cell discharge. Other male factors, which are involved in pollen tube growth and reception, are the pollenexpressed transcription factors MYB97, MYB101 and MYB120. myb97/101/120 triple mutants exhibited uncontrolled growth and failed to discharge their sperm cells after entering the embryo sac (Liang et al., 2013). It is thought that these factors are required to enable pollen tube to communicate with the pistil tissues and the female gametophyte (Leydon et al., 2014). As already mentioned, the level of $\mathrm{Ca}_{\text {cyto }}^{2+}$ alters during pollen tube elongation. Upon pollen tube arrival $\mathrm{Ca}_{\text {cyto }}^{2+}$ level starts to oscillate in the 
synergid cells, triggered by the contact of the pollen tube tip with the synergid cell. This oscillation can be observed until pollen tube burst, which leads to the degeneration of one synergid cell (Sandaklie-Nikolova et al., 2007; Iwano et al., 2012; Denninger et al., 2014; Ngo et al., 2014). These changes in $\mathrm{Ca}_{\text {cyto }}^{2+}$ level are essential for sperm delivery and are depending on FER and LRE activity, respectively. Downstream of FER, NTA localization to the synergid cell surface and its activity likely depend on sufficient $\mathrm{Ca}_{\text {cyto }}^{2+}$ level in the synergid cells (Ngo et al., 2014). The synergid cell, which is in contact with the pollen tube follows a regulated cell death program that is somehow associated and controlled by pollen tube burst and linked to oscillation of $\mathrm{Ca}_{\text {cyto }}^{2+}$ level (Higashiyama et al., 2000; Sandaklie-Nikolova et al., 2007; Denninger et al., 2014; Ngo et al., 2014). It cannot be explained by mechanical breakdown due to an invading pollen tube. In fer mutant, for example, pollen tube growth continues around the synergid cells, which must be associated with mechanical stress but does not induce synergid cell death (Escobar-Restrepo et al., 2007). However, the signaling events, which are responsible for programmed cell death in the synergid cell, are not understood yet. In maize pollen tube arrival is associated with the secretion of defensin-like $\mathrm{ZmES}$ proteins, inducing pollen tube burst by activating the $\mathrm{K}^{+}$-channel Zea mays 1 (KZM1) in the pollen tube membrane (Amien et al., 2010). Whether these "toxin"-like molecules are also capable of inducing synergid cell burst remains to be shown.

\section{GAMETE INTERACTION AND PREVENTION OF POLYSPERMY SPERM CELL DELIVERY, ACTIVATION, AND GAMETIC MEMBRANE INTERACTIONS}

Once released, the two sperm cells are delivered to the so-called gamete fusion site between egg and central cell (Figure 2B). It is controversial whether this requires active transport or is solely based on cytoplasmic flow associated with burst of both pollen tube and receptive synergid cell and/or the architecture of the egg apparatus. Most flowering plants, like Arabidopsis, generate isomorphic sperm cells and therefore fusion of sperm cell appears to be random, either with the egg or the central cell (Berger et al., 2008; Ingouff et al., 2009; Liu et al., 2010). Some reports suggest that fertilization of the egg cell is preferred, which was demonstrated, for example, in mutants of CYCLIN DEPENDENT KINASE A1 (CDKA;1), which generate only one sperm-like germ cell (Iwakawa et al., 2006; Nowack et al., 2006). Experiments with photo-labeled sperm cells have demonstrated that there is no preference for either female gamete (Hamamura et al., 2011). The differentiation into two equal sperm cells depends on the activity of the MYB transcription factor DUO POLLEN 1 (DUO1), which is required for correct male germ cell differentiation by regulating key genes essential for fertilization such as GAMETE EXPRESSED 2 (GEX2) and GENERATIVE CELL SPECIFIC 1 (GCS1), also known as HAPLESS 2 (HAP2) (Brownfield et al., 2009). GEX2 encodes a single-pass transmembrane protein with filamin repeats exposed to the extracellular space. GEX2 localizes to the sperm cell plasma membrane and contains extracellular immunoglobulin-like domains, similar to gamete interaction factors reported in algae and mammals (Misamore et al., 2003; Inoue et al., 2005). In the presence of GEX2 the two gametes adhere to the egg and central cell. gex2 mutant sperm cells show reduced adhesion to female gametes, likely causing cell fusion failure (Mori et al., 2014). GCS1/HAP2 is another factor required for gamete interaction in Arabidopsis. After pollen tube burst, both sperm cells of gcs1/hap2 loss of function mutants remain at the fusion site and fail to fuse with female gametes, leading to the attraction of additional pollen tubes (polytubey). It was further shown that in the absence of the potential fusogen GCS1/HAP2, attachment of male to the female gamete occurs but no membrane fusion is visible, implying that the protein mediates membrane fusion as a component of signaling events, or more likely that it is directly involved in the fusion event (Wong and Johnson, 2010; Mori et al., 2014). GCS1/HAP2 is a conserved protein and has been identified in genomes of all major eukaryotic taxa except fungi. Gcs1/hap2 mutants in protozoan and algal gametes result in fusion failure, suggesting that this protein is required for a common mechanism of membrane fusion in eukaryotes (Mori et al., 2006; Hirai et al., 2008; Liu et al., 2008; Steele and Dana, 2009; Wong and Johnson, 2010). Upon sperm cell arrival at the gamete fusion site (Figure 2B) the egg cell starts to secrete small cysteine-rich proteins of the EGG CELL 1 (EC1) family. EC1 leads to the relocalization of HAP2/GCS1 from the endomembrane system to the sperm cell plasma membrane and thus activates sperm cells enabling them to fuse with the female gametes (Sprunck et al., 2012). The egg cell appears to require activation itself and calcium may play a key role in this process; this is indicated by a single strong $\mathrm{Ca}_{\text {cyto }}^{2+}$ transient in the egg cell associated with pollen tube burst and sperm delivery (Denninger et al., 2014), which thus precedes EC1 secretion.

The relocalization of a transmembrane fusogen was also described for the mammalian-specific fusogen IZUMO1 (Inoue et al., 2005). Female components, which are directly involved in gamete fusion are so far unknown in higher plants. In mammals, CD9-like membrane spanning proteins of the tetraspanin family are located at the plasma membrane of eggs and were shown to be required for gamete fusion (Kaji et al., 2000; Le Naour et al., 2000; Miyado et al., 2000). In Arabidopsis the conserved tetraspanin family consists of 17 members. While TET11 and especially TET12 are located at the surface of sperm cells and reach high concentrations in the membrane region connecting both sperm cells, TET9 appears at the surface of female gametophyte cells including the egg and central cell (Boavida et al., 2013). Arabidopsis tetraspanins were shown to form homo- and heterodimers, but so far functional studies are missing. However, their presence at the surface of plant gametes and structural homology to mammalian CD9-like proteins suggest that they may possess a similar role during gamete interaction.

\section{DEGRADATION OF FUSOGENS AND PREVENTION OF POLYSPERMY}

In general polyspermy blocks prevent multiple fertilization events that would otherwise lead to abnormal development or even embryo lethality, and thus reproductive failure. In Chlamydomonas FUS1, a single-pass transmembrane protein with a high similarity to prokaryotic invasion and adhesion molecules, mediates membrane fusion (Ferris et al., 1996; Misamore et al., 2003). In Chlamydomonas both GCS1/HAP2 and FUS1 are rapidly degraded after cell fusion, resulting in a fast membrane 
block to prevent polygamy (Misamore et al., 2003; Liu et al., 2010). In mammals, it was recently shown that IZUMO1 is recognized by the GPI-anchored protein JUNO on the egg cell surface. Rapid degradation of JUNO after fertilization suggests an additional mechanism for membrane block to prevent polyspermy (Bianchi et al., 2014).

In Arabidopsis it was shown that the polyspermy block only functions in the egg cell and not in the central cell, which is capable of fusing with more than one sperm cell, as demonstrated in the tetraspore (tes) mutant. This mutant produces more than one sperm pair, which is released simultaneously at the gamete fusion site. After fertilization, polyploidy resulting from multiple fertilization events was observed in the developing endosperm, but not in the embryo (Scott et al., 2008). The cause of the egg cell-specific fast block to polyspermy is unclear. In vitro fertilization experiments with maize egg and sperm cells have shown that cell wall material is detectable already within $30 \mathrm{sec}$ after fusion (Kranz et al., 1995) and thus may prevent further gametic membrane interactions. Additionally, a quick block to polyspermy may also depend on the degradation of fusogens as described above. Calcium may play a role in immediate signaling of successful plasmogamy and release of cell wall material as an extended $\mathrm{Ca}_{\text {cyto }}^{2+}$ transient is observed in the egg cell associated with successful gamete fusion (Denninger et al., 2014). However, the precise cellular function of calcium signaling during gamete interaction is currently unclear and will require further experimentation.

Another way to prevent polyspermy is the deactivation of pollen tube guidance and the activation of repelling mechanisms. In Arabidopsis usually only a single pollen tube is guided inside the ovule to execute double fertilization. After unsuccessful fertilization events, for example by failure of cell-cell fusion in $g c s 1 / h a p 2$, duo1, duo3, gex2, cdka;1, or ec1-RNAi gametes (Beale et al., 2012; Kasahara et al., 2012; Sprunck et al., 2012; Maruyama et al., 2013; Mori et al., 2014), secondary pollen tubes are attracted by the remaining synergid cell by a process named as polytubey. This process is delayed by a couple of hours (Kasahara et al., 2012), suggesting that pollen tube repellents are released upon sperm cell discharge and require degradation until additional pollen tubes can be attracted by the remaining synergid cell. After successful fertilization this cell quickly disintegrates, but remains viable for significantly longer times upon fertilization failure (Beale et al., 2012). A recent report showed that both female gametes independently control successful fertilization thus maximizing reproductive success (Maruyama et al., 2013). The key to prevent polytubey is the quick degeneration of the 2 nd synergid cell. In order to investigate its death, it was recently reported that an EthyleneInsensitive (EIN3-EIN2)/Ethylene-Insensitive3-like2 (EIL2)dependent, ethylene-response cascade is activated after fertilization. Its artificial activation results in premature synergid cell disintegration and thus a block to pollen tube attraction (Völz et al., 2013). The degeneration of the 2 nd synergid cell thus leads to the stop of attractant secretion and ultimately prevents polyspermy.

\section{ACTIVATION OF SEED DEVELOPMENT}

Both female gametes need to be fertilized to produce viable progeny. Although equipped with the genetic repertoire to generate every cell type (in the case of the fertilized egg cell) or a number of highly specialized cell types (in the case of the fertilized central cell), both female gametes appear in an arrested state until activated through fertilization. In contrast, parthenogenetic egg cells do not arrest and initiate cell division without fertilization. The central cell, however, requires fertilization in most plant species, even in those containing parthenogenetic egg cells. Its activation is closely related to seed development as both parthenogenetic embryogenesis and seed development arrest at an early stage without central cell fertilization (Koltunow and Grossniklaus, 2003; Barcaccia and Albertini, 2013). Recent reports in Arabidopsis confirm intensive cross-talk between endosperm and embryo as well as between endosperm and seed coat shortly after fertilization (Costa et al., 2014; Figueiredo and Köhler, 2014). It was further shown that the zygotic genome is activated shortly after fertilization in this species and both maternal and paternal genomes contribute equally to the transcriptome of the early embryo (Nodine and Bartel, 2012). Research in the last two decades has discovered many differences in epigenetic modification between male and female genomes, which lead to variations in expression profiles between their genes before and after fertilization. Polycomb group genes and RNA silencing mechanisms play a major role in these processes, but will not be considered here in more detail as excellent reviews can be found elsewhere (e.g., Van Ex et al., 2011; Gehring, 2013).

It is well conceivable that sperm cells deliver factors, which activate female gametes after fusion. A transcript encoding the Interleukin-1 Receptor-Associated Kinase (IRAK)/Pelle-like kinase gene SHORT SUSPENSOR (SSP), which was shown to be delivered by sperm cells, becomes translated in the zygote and acts in the YODA (YDA) MAPK pathway during zygote elongation (Bayer et al., 2009). In the zygote, the regulatory network activated by SSP-YDA is yet unknown. Activation of the cell cycle might also represent a key mechanism for the activation and progression of seed development. However, $c d k a ; 1$ mutant single sperm-like germ cells, defective in a master cell cycle regulator are capable of fertilizing egg cells and activating the embryonic program (Iwakawa et al., 2006; Nowack et al., 2006). Although the mutant $c d k a ; 1$ central cell showed mitotic divisions upon egg cell fertilization, it appeared mostly unfertilized, and endosperm proliferation and thereby seed development stopped after a certain time point. This finding suggested a positive proliferation signal from the zygote leading to cell cycle activation in the central cell. However, occasionally two $c d k a ; 1$ sperm cells are delivered to the gamete fusion site leading to cell-cell fusion of both female gametes with one $c d k a ; 1$ mutant sperm cell each. It was further reported that fusion between nuclei of sperm and central cell fails. The failure of karyogamy in the central cell prevents incorporation of the paternal genome, impairs endosperm development and causes seed abortion. This and the above findings using pathenogenetic species imply that the paternal genome plays an essential role during early seed development and that sperm cell factors are also required to activate central cell development (Aw et al., 2010). In summary, very little is known about the molecular mechanisms activating both female gametes that lead to the initiation of seed development. 


\section{CONCLUSIONS}

Efficient and successful fertilization of all developed ovules is a key to reproductive success and essential for high crop yield. Using the model plant Arabidopsis tremendous progress has been made in the past couple of years to understand the underlying cellular and molecular mechanisms that regulate pollen tube growth and guidance, sperm delivery and gamete interaction resulting in blocks to polytubey and polyspermy. Little is known about the activation of gametes and thus seed development immediately after fertilization. Many of the processes described above involve conserved mechanisms and proteins. Some of these proteins are highly polymorphic and species-specific, allowing female flower organs to discriminate self from alien pollen grains/pollen tubes to avoid reproductive failure after pollination and fertilization with incompatible gametophytes and gametes, respectively. In summary, we have learned that species-specific or even ecotype-specific molecules and plant family-specific mechanisms are required during compatible interactions. These are used by papilla cells to control pollen germination, by transmitting tract cells during pollen tube growth and by the ovule and female gametophyte cells during the last steps of pollen tube journey. Moreover, even sperm cell discharge is regulated in a speciespreferential manner. Whether gamete interactions depend on species-specific molecules remains to be shown. Up to now the final processes of fertilization seem to involve partly conserved proteins even from lower to higher eukaryotes. The knowledge generated can now be used to investigate, for example, speciation mechanisms or can be applied to overcome hybridization barriers between species. Initial attempts enabling ovules to attract pollen tubes from unrelated plant families have been successful (Márton et al., 2012). However, as outlined above double fertilization mechanisms are very complex and regulated at multiple levels, and it will be a challenge to overcome all steps simultaneously allowing wide hybridization between plant species that presently cannot be crossed. A major challenge for the near future is to understand fertilization mechanisms also in crop plants, especially in the grasses, which represent the most economically important plant family. Maize was suggested as a grass and crop model to investigate these processes (Dresselhaus et al., 2011), but transformation difficulties, the low number of available insertion mutants, the requirement of sufficient greenhouse space and especially technical problems to visualize the fertilization process in vivo still limit its utilization for reproduction biologists. Concerted efforts are now required to understand the molecular mechanisms of double fertilization in crop plants, which significantly differ from Arabidopsis in both reproductive structures and genetic repertoire.

\section{ACKNOWLEDGMENTS}

We acknowledge Erhard Strohm for his support in 3D modeling of Arabidopsis ovules. Work in the Dresselhaus lab is supported by grants from the German Research Council (DFG) via the Collaborative Research Centers SFB924 und SFB960.

\section{SUPPLEMENTARY MATERIAL}

The Supplementary Material for this article can be found online at: http://www.frontiersin.org/journal/10.3389/fpls.2014.00452/ abstract

\section{REFERENCES}

Alandete-Saez, M., Ron, M., and McCormick, S. (2008). GEX3, expressed in the male gametophyte and in the egg cell of Arabidopsis thaliana, is essential for micropylar pollen tube guidance and plays a role during early embryogenesis. Mol. Plant 1, 586-598. doi: 10.1093/mp/ssn015

Amien, S., Kliwer, I., Márton, M. L., Debener, T., Geiger, D., Becker, D., et al. (2010). Defensin-like ZmES4 mediates pollen tube burst in maize via opening of the potassium channel KZM1. PLoS Biol. 8:e1000388. doi: 10.1371/journal.pbio. 1000388

Aw, S. J., Hamamura, Y., Chen, Z., Schnittger, A., and Berger, F. (2010). Sperm entry is sufficient to trigger division of the central cell but the paternal genome is required for endosperm development in Arabidopsis. Development 137, 2683-2690. doi: 10.1242/dev.052928

Barcaccia, G., and Albertini, E. (2013). Apomixis in plant reproduction: a novel perspective on an old dilemma. Plant Reprod. 26, 159-179. doi: 10.1007/s00497013-0222-y

Bayer, M., Nawy, T., Giglione, C., Galli, M., Meinnel, T., and Lukowitz, W. (2009). Paternal control of embryonic patterning in Arabidopsis thaliana. Science 323, 1485-1488. doi: 10.1126/science.1167784

Beale, K. M., Leydon, A. R., and Johnson, M. (2012). Gamete fusion is required to block multiple pollen tubes from entering an Arabidopsis ovule. Curr. Biol. 22, 1090-1094. doi: 10.1016/j.cub.2012.04.041

Berger, F., Hamamura, Y., Ingouff, M., and Higashiyama, T. (2008). Double fertilization - caught in the act. Trends Plant Sci. 13, 437-443. doi: 10.1016/j.tplants. 2008.05.011

Bianchi, E., Doe, B., Goulding, D., and Wright, G. J. (2014). Juno is the egg Izumo receptor and is essential for mammalian fertilization. Nature 508, 483-487. doi: 10.1038/nature13203

Boavida, L. C., Qin, P., Broz, M., Becker, J. D., and McCormick, S. (2013). Arabidopsis tetraspanins are confined to discrete expression domains and cell types in reproductive tissues and form homo- and heterodimers when expressed in yeast. Plant Physiol. 163, 696-712. doi: 10.1104/pp.113.216598

Boisson-Dernier, A., Lituiev, D. S., Nestorova, A., Franck, C. M., Thirugnanarajah, S., and Grossniklaus, U. (2013). ANXUR receptor-like kinases coordinate cell wall integrity with growth at the pollen tube tip via NADPH oxidases. PLoS Biol. 11:e1001719. doi: 10.1371/journal.pbio.1001719

Boisson-Dernier, A., Roy, S., Kritsas, K., Grobei, M. A., Jaciubek, M., Schroeder, J. I., et al. (2009). Disruption of the pollen-expressed FERONIA homologs ANXUR1 and ANXUR2 triggers pollen tube discharge. Development 136, 3279-3288. doi: 10.1242/dev.040071

Brewbaker, J. L., and Kwack, B. H. (1963). The essential role of calcium ion in pollen germination and pollen tube growth. Am. J. Bot. 50, 859-865. doi: 10.2307/ 2439772

Brownfield, L., Hafidh, S., Borg, M., Sidorova, A., Mori, T., and Twell, D. (2009). A plant germline-specific integrator of sperm specification and cell cycle progression. PLoS Genet. 5:e1000430. doi: 10.1371/journal.pgen.1000430

Calder, G. M., Franklin-Tong, V. E., Shaw, P. J., and Drøbak, B. K. (1997). Ca2+ oscillations in plant cells: initiation by rapid elevation in cytosolic free $\mathrm{Ca}^{2+} \mathrm{lev}$ els. Biochem. Biophys. Res. Commun. 234, 690-694. doi: 10.1006/bbrc.1997.6514

Capron, A., Gourgues, M., Neiva, L. S., Faure, J. -E., Berger, F., Pagnussat, G., et al. (2008). Maternal control of male-gamete delivery in Arabidopsis involves a putative GPI-anchored protein encoded by the LORELEI gene. Plant Cell 20, 3038-3049. doi: 10.1105/tpc.108.061713

Chaubal, R., and Reger, B. (1990). Relatively high calcium is localized in synergid cells of wheat ovaries. Sex. Plant Reprod. 3, 98-102.

Chen, Y.-H., Li, H.-J., Shi, D.-Q., Yuan, L., Liu, J., Sreenivasan, R., et al. (2007). The central cell plays a critical role in pollen tube guidance in Arabidopsis. Plant Cell 19, 3563-3577. doi: 10.1105/tpc.107.053967

Cosgrove, D. J., Bedinger, P., and Durachko, D. M. (1997). Group I allergens of grass pollen as cell wall-loosening agents. Proc. Natl. Acad. Sci. U.S.A. 94, 6559-6564. doi: 10.1073/pnas.94.12.6559

Costa, L. M., Marshall, E., Tesfaye, M., Silverstein, K. A., Mori, M., Umetsu, Y., et al. (2014). Central cell-derived peptides regulate early embryo patterning in flowering plants. Science 344, 168-172. doi: 10.1126/science.1243005

Crawford, B. C. W., Ditta, G., and Yanofsky, M. F. (2007). The NTT gene is required for transmitting-tract development in carpels of Arabidopsis thaliana. Curr. Biol. 17, 1101-1108. doi: 10.1016/j.cub.2007.05.079

Crawford, B. C. W., and Yanofsky, M. F. (2011). HALF FILLED promotes reproductive tract development and fertilization efficiency in Arabidopsis thaliana. Development 138, 2999-3009. doi: 10.1242/dev.067793 
Denninger, P., Bleckmann, A., Lausser, A., Vogler, F., Ott, T., Ehrhardt, D., et al. (2014). Male-female communication triggers calcium signatures during fertilization in Arabidopsis. Nat. Commun. 5:4645. doi: 10.1038/ncomms5645

Diboll, A. G., and Larson, D. A. (1966). An electron microscopic study of the mature megagametophyte in Zea mays. Am. J. Bot. 53, 391-402. doi: 10.2307/ 2439880

Dresselhaus, T., and Franklin-Tong, N. (2013). Male-female crosstalk during pollen germination, tube growth and guidance, and double fertilization. Mol. Plant 6, 1018-1036. doi: 10.1093/mp/sst061

Dresselhaus, T., Lausser, A., and Márton, M. L. (2011). Using maize as a model to study pollen tube growth and guidance, cross-incompatibility and sperm delivery in grasses. Ann. Bot. 108, 727-737. doi: 10.1093/aob/mcr017

Drews, G. N., and Koltunow, A. M. G. (2011). The female gametophyte. Arabidopsis Book 9:e0155. doi: 10.1199/tab.0155

Drews, G. N., Lee, D., and Christensen, C. A. (1998). Genetic analysis of female gametophyte development and function. Plant Cell 10, 5-17. doi: 10.1105/tpc. 10.1.5

Escobar-Restrepo, J.-M., Huck, N., Kessler, S., Gagliardini, V., Gheyselinck, J., Yang, W.-C., et al. (2007). The FERONIA receptor-like kinase mediates malefemale interactions during pollen tube reception. Science 317, 656-660. doi: 10.1126/science. 1143562

Evans, M. M. S., and Grossniklaus, U. (2009). “The maize megagametophyte," in Handbook of Maize: Its Biology, eds J. L. Bennetzen and S. C. Hake (New York, NY: Springer New York), 79-104.

Ferris, P. J., Woessner, J. P., and Goodenough, U. W. (1996). A sex recognition glycoprotein is encoded by the plus mating-type gene fusl of Chlamydomonas reinhardtii. Mol. Biol. Cell 7, 1235-1248. doi: 10.1091/mbc.7.8.1235

Figueiredo, D. D., and Köhler, C. (2014). Signalling events regulating seed coat development. Biochem. Soc. Trans. 42, 358-363. doi: 10.1042/BST20130221

Gehring, M. (2013). Genomic imprinting: insights from plants. Annu. Rev. Genet. 47, 187-208. doi: 10.1146/annurev-genet-110711-155527

Gilliham, M., Campbell, M., Dubos, C., Becker, D., and Davenport, R. (2006). "The Arabidopsis thaliana Glutamate-like Receptor Family (AtGLR)," in Communication in Plants, eds F. Baluška, S. Mancuso, and D. Volkmann (Berlin, Heidelberg: Springer Berlin Heidelberg), 205-222.

Grobe, K., Becker, W. M., Schlaak, M., and Petersen, A. (1999). Grass group I allergens (beta-expansins) are novel, papain-related proteinases. Eur. J. Biochem. 263, 33-40. doi: 10.1046/j.1432-1327.1999.00462.x

Guan, Y., Lu, J., Xu, J., McClure, B., and Zhang, S. (2014). Two mitogen-activated protein kinases, MPK3 and MPK6, are required for funicular guidance of pollen tubes in Arabidopsis. Plant Physiol. 165, 528-533. doi: 10.1104/pp 113.231274

Hamamura, Y., Saito, C., Awai, C., Kurihara, D., Miyawaki, A., Nakagawa, T., et al. (2011). Live-cell imaging reveals the dynamics of two sperm cells during double fertilization in Arabidopsis thaliana. Curr. Biol. 21, 497-502. doi: 10.1016/j.cub.2011.02.013

Haruta, M., and Constabel, C. P. (2003). Rapid alkalinization factors in poplar cell cultures. Peptide isolation, cDNA cloning, and differential expression in leaves and methyl jasmonate-treated cells. Plant Physiol. 131, 814-823. doi: 10.1104/pp.014597

Haruta, M., Monshausen, G., Gilroy, S., and Sussman, M. R. (2008). A cytoplasmic $\mathrm{Ca}^{2+}$ functional assay for identifying and purifying endogenous cell signaling peptides in Arabidopsis seedlings: identification of AtRALF1 peptide. Biochemistry 47, 6311-6321. doi: 10.1021/bi8001488

Haruta, M., Sabat, G., Stecker, K., Minkoff, B. B., and Sussman, M. R. (2014). A peptide hormone and its receptor protein kinase regulate plant cell expansion. Science 343, 408-411. doi: 10.1126/science.1244454

Higashiyama, T., Kuroiwa, H., Kawano, S., and Kuroiwa, T. (1998). Guidance in vitro of the pollen tube to the naked embryo sac of Torenia fournieri. Plant Cell 10, 2019-2032. doi: 10.1105/tpc.10.12.2019

Higashiyama, T., Kuroiwa, H., Kawano, S., and Kuroiwa, T. (2000). Explosive discharge of pollen tube contents in Torenia fournieri. Plant Physiol. 122, 11-14. doi: $10.1104 /$ pp.122.1.11

Higashiyama, T., Yabe, S., Sasaki, N., Nishimura, Y., Miyagishima, S, Kuroiwa, H., et al. (2001). Pollen tube attraction by the synergid cell. Science 293, 1480-1483. doi: 10.1126/science.1062429

Hirai, M., Arai, M., Mori, T., Miyagishima, S.-Y., Kawai, S., Kita, K., et al. (2008). Male fertility of malaria parasites is determined by GCS1, a plant-type reproduction factor. Curr. Biol. 18, 607-613. doi: 10.1016/j.cub.2008.03.045
Hua, Z., and Kao, T.-H. (2006). Identification and characterization of components of a putative petunia S-locus F-box-containing E3 ligase complex involved in S-RNase-based self-incompatibility. Plant Cell 18, 2531-2553. doi: 10.1105/tpc.106.041061

Huang, B.-Q., and Russell, S. D. (1992). Female germ unit: organization, isolation, and function. Int. Rev. Cytol. 140, 233-292. doi: 10.1016/s0074-7696 (08)61099-2

Huck, N., Moore, J. M., Federer, M., and Grossniklaus, U. (2003). The Arabidopsis mutant feronia disrupts the female gametophytic control of pollen tube reception. Development 130, 2149-2159. doi: 10.1242/dev.00458

Ingouff, M., Sakata, T., Li, J., Sprunck, S., Dresselhaus, T., and Berger, F. (2009). The two male gametes share equal ability to fertilize the egg cell in Arabidopsis thaliana. Curr. Biol. 19, R19-R20. doi: 10.1016/j.cub.2008.11.025

Inoue, N., Ikawa, M., Isotani, A., and Okabe, M. (2005). The immunoglobulin superfamily protein Izumo is required for sperm to fuse with eggs. Nature 434, 234-438. doi: 10.1038/nature03362

Iwakawa, H., Shinmyo, A., and Sekine, M. (2006). Arabidopsis CDKA;1, a cdc2 homologue, controls proliferation of generative cells in male gametogenesis. Plant J. 45, 819-831. doi: 10.1111/j.1365-313X.2005.02643.x

Iwano, M., Igarashi, M., Tarutani, Y., Kaothien-Nakayama, P., Nakayama, H., Moriyama, H., et al. (2014). A pollen coat-inducible autoinhibited $\mathrm{Ca}^{2+}$-ATPase expressed in stigmatic papilla cells is required for compatible pollination in the Brassicaceae. Plant Cell 26, 636-649. doi: 10.1105/tpc.113.121350

Iwano, M., Ngo, Q., Entani, T., Shiba, H., Nagai, T., Miyawaki, A., et al. (2012). Cytoplasmic $\mathrm{Ca}^{2+}$ changes dynamically during the interaction of the pollen tube with synergid cells. Development 139, 4202-4209. doi: 10.1242/dev.081208

Iwano, M., Shiba, H., Miwa, T., Che, F., Takayama, S., Nagai, T., et al. (2004). Ca ${ }^{2+}$ dynamics in a pollen grain and papilla cell during pollination of Arabidopsis. Plant Physiol. 136, 3562-3571. doi: 10.1104/pp.104.046961

Iwano, M., and Takayama, S. (2012). Self/non-self discrimination in angiosperm self-incompatibility. Curr. Opin. Plant Biol. 15, 78-83. doi: 10.1016/j.pbi.2011. 09.003

Kaji, K., Oda, S., Shikano, T., Ohnuki, T., Uematsu, Y., Sakagami, J., et al. (2000). The gamete fusion process is defective in eggs of Cd9-deficient mice. Nat. Genet. 24, 279-282. doi: 10.1038/73502

Kanaoka, M. M., Kawano, N., Matsubara, Y., Susaki, D., Okuda, S., Sasaki, N., et al. (2011). Identification and characterization of TcCRP1, a pollen tube attractant from Torenia concolor. Ann. Bot. 108, 739-747. doi: 10.1093/aob/mcr111

Kasahara, R. D., Maruyama, D., Hamamura, Y., Sakakibara, T., Twell, D., and Higashiyama, T. (2012). Fertilization recovery after defective sperm cell release in Arabidopsis. Curr. Biol. 22, 1084-1089. doi: 10.1016/j.cub.2012.03.069

Kasahara, R. D., Portereiko, M. F., Sandaklie-Nikolova, L., Rabiger, D. S., and Drews, G. N. (2005). MYB98 is required for pollen tube guidance and synergid cell differentiation in Arabidopsis. Plant Cell 17, 2981-2992. doi: 10.1105/tpc.105.034603

Kessler, S. A., Shimosato-Asano, H., Keinath, N. F., Wuest, S. E., Ingram, G., Panstruga, R., et al. (2010). Conserved molecular components for pollen tube reception and fungal invasion. Science 330, 968-971. doi: 10.1126/science. 1195211

Kim, S., Mollet, J.-C., Dong, J., Zhang, K., Park, S.-Y., and Lord, E. M. (2003). Chemocyanin, a small basic protein from the lily stigma, induces pollen tube chemotropism. Proc. Natl. Acad. Sci. U.S.A. 100, 16125-16130. doi: $10.1073 /$ pnas. 2533800100

Koltunow, A. M., and Grossniklaus, U. (2003). Apomixis: a developmental perspective. Annu. Rev. Plant Biol. 54, 547-574. doi: 10.1146/annurev.arplant.54. 110901.160842

Kranz, E., Wiegen, P., and Lörz, H. (1995). Early cytological events after induction of cell division in egg cells and zygote development following in vitro fertilization with angiosperm gametes. Plant J. 8, 9-23. doi: 10.1046/j.1365313X.1995.08010009.x

Kubo, K., Entani, T., Takara, A., Wang, N., Fields, A. M., Hua, Z., et al. (2010). Collaborative non-self recognition system in S-RNase-based selfincompatibility. Science 330, 796-799. doi: 10.1126/science.1195243

Lausser, A., and Dresselhaus, T. (2010). Sporophytic control of pollen tube growth and guidance in grasses. Biochem. Soc. Trans. 38, 631-634. doi: 10.1042/BST0380631

Le Naour, F., Rubinstein, E., Jasmin, C., Prenant, M., and Boucheix, C. (2000). Severely reduced female fertility in CD9-deficient mice. Science 287, 319-321. doi: $10.1126 /$ science.287.5451.319 
Lennon, K. A., Roy, S., Hepler, P. K., and Lord, E. M. (1998). The structure of the transmitting tissue of Arabidopsis thaliana (L.) and the path of pollen tube growth. Sex. Plant Reprod. 11, 49-59. doi: 10.1007/s004970050120

Leshem, Y., Johnson, C., and Sundaresan, V. (2013). Pollen tube entry into the synergid cell of Arabidopsis is observed at a site distinct from the filiform apparatus. Plant Reprod. 26, 93-99. doi: 10.1007/s00497-013-0211-1

Leydon, A. R., Beale, K. M., Woroniecka, K., Castner, E., Chen, J., Horgan, C., et al. (2013). Three MYB transcription factors control pollen tube differentiation required for sperm release. Curr. Biol. 23, 1209-1214. doi: 10.1016/j.cub.2013.05.021

Leydon, A. R., Chaibang, A., and Johnson, M. (2014). Interactions between pollen tube and pistil control pollen tube identity and sperm release in the Arabidopsis female gametophyte. Biochem. Soc. Trans. 42, 340-345. doi: 10.1042/BST20130223

Liang, Y., Tan, Z.-M., Zhu, L., Niu, Q.-K., Zhou, J.-J., Li, M., et al. (2013). MYB97, MYB101 and MYB120 function as male factors that control pollen tube-synergid interaction in Arabidopsis thaliana fertilization. PLoS Genet. 9:e1003933. doi: 10.1371/journal.pgen.1003933

Liu, J., Zhong, S., Guo, X., Hao, L., Wei, X., Huang, Q., et al. (2013). Membranebound RLCKs LIP1 and LIP2 are essential male factors controlling male-female attraction in Arabidopsis. Curr. Biol. 23, 993-998. doi: 10.1016/j.cub.2013.04.043

Liu, Y., Misamore, M. J., and Snell, W. J. (2010). Membrane fusion triggers rapid degradation of two gamete-specific, fusion-essential proteins in a membrane block to polygamy in Chlamydomonas. Development 137, 1473-1481. doi: 10.1242/dev.044743

Liu, Y., Tewari, R., Ning, J., Blagborough, A. M., Garbom, S., Pei, J., et al. (2008). The conserved plant sterility gene HAP2 functions after attachment of fusogenic membranes in Chlamydomonas and Plasmodium gametes. Genes Dev. 22, 1051-1068. doi: 10.1101/gad.1656508

Liu, Z.-Q., Xu, G.-H., and Zhang, S.-L. (2007). Pyrus pyrifolia stylar S-RNase induces alterations in the actin cytoskeleton in self-pollen and tubes in vitro. Protoplasma 232, 61-67. doi: 10.1007/s00709-007-0269-4

Lush, W., Grieser, F., and Wolters-Arts, M. (1998). Directional guidance of Nicotiana alata pollen tubes in vitro and on the stigma. Plant Physiol. 118, 733-741. doi: 10.1104/pp.118.3.733

Luu, D. T., Qin, X., Morse, D., and Cappadocia, M. (2000). S-RNase uptake by compatible pollen tubes in gametophytic self-incompatibility. Nature 407, 649-651. doi: $10.1038 / 35036623$

Mansfield, S. G., Briarty, L. G., and Erni, S. (1991). Early embryogenesis in Arabidopsis thaliana. I. The mature embryo sac. Can. J. Bot. 69, 447-460. doi: 10.1139/b91-062

Márton, M. L., Cordts, S., Broadhvest, J., and Dresselhaus, T. (2005). Micropylar pollen tube guidance by egg apparatus 1 of maize. Science 307, 573-576. doi: 10.1126/science.1104954

Márton, M. L., Fastner, A., Uebler, S., and Dresselhaus, T. (2012). Overcoming hybridization barriers by the secretion of the maize pollen tube attractant ZmEA1 from Arabidopsis ovules. Curr. Biol. 22, 1194-1198. doi: 10.1016/j.cub.2012.04.061

Maruyama, D., Hamamura, Y., Takeuchi, H., Susaki, D., Nishimaki, M., Kurihara, D., et al. (2013). Independent control by each female gamete prevents the attraction of multiple pollen tubes. Dev. Cell 25, 317-323. doi: 10.1016/j.devcel.2013.03.013

Matias-Hernandez, L., Battaglia, R., Galbiati, F., Rubes, M., Eichenberger, C., Grossniklaus, U., et al. (2010). VERDANDI is a direct target of the MADS domain ovule identity complex and affects embryo sac differentiation in Arabidopsis. Plant Cell 22, 1702-1715. doi: 10.1105/tpc.109.068627

McClure, B. A., Haring, V., Ebert, P. R., Anderson, M. A., Simpson, R. J., Sakiyama, F., et al. (1989). Style self-incompatibility gene products of Nicotiana alata are ribonucleases. Nature 342, 955-957. doi: 10.1038/342955a0

McCue, A. D., Cresti, M., Feijó, J. A., and Slotkin, R. K. (2011). Cytoplasmic connection of sperm cells to the pollen vegetative cell nucleus: potential roles of the male germ unit revisited. J. Exp. Bot. 62, 1621-1631. doi: 10.1093/jxb/ err032

Michard, E., Lima, P. T., Borges, F., Silva, A. C., Portes, M. T., Carvalho, J. E., et al. (2011). Glutamate receptor-like genes form $\mathrm{Ca}^{2+}$ channels in pollen tubes and are regulated by pistil D-serine. Science 332, 434-437. doi: 10.1126/science. 1201101

Miller, D. D., Callaham, D. A., Gross, D. J., and Hepler, P. K. (1992). Free $\mathrm{Ca}^{2+}$ gradient in growing pollen tubes of Lillium. J. Cell Sci. 101, 7-12.
Misamore, M. J., Gupta, S., and Snell, W. J. (2003). The Chlamydomonas Fus1 protein is present on the mating type plus fusion organelle and required for a critical membrane adhesion event during fusion with minus gametes. Mol. Biol. Cell 14, 2530-2542. doi: 10.1091/mbc.E02-12-0790

Miyado, K., Yamada, G., Yamada, S., Hasuwa, H., Nakamura, Y., Ryu, F., et al. (2000). Requirement of CD9 on the egg plasma membrane for fertilization. Science 287, 321-324. doi: 10.1126/science.287.5451.321

Miyazaki, S., Murata, T., Sakurai-Ozato, N., Kubo, M., Demura, T., Fukuda, H., et al. (2009). ANXUR1 and 2, sister genes to FERONIA/SIRENE, are male factors for coordinated fertilization. Curr. Biol. 19, 1327-1331. doi: 10.1016/j.cub.2009.06.064

Mori, T., Igawa, T., Tamiya, G., Miyagishima, S.-Y., and Berger, F. (2014). Gamete attachment requires GEX2 for successful fertilization in Arabidopsis. Curr. Biol. 24, 170-175. doi: 10.1016/j.cub.2013.11.030

Mori, T., Kuroiwa, H., Higashiyama, T., and Kuroiwa, T. (2006). GENERATIVE CELL SPECIFIC 1 is essential for angiosperm fertilization. Nat. Cell Biol. 8, 64-71. doi: 10.1038/ncb1345

Ngo, Q. A., Vogler, H., Lituiev, D. S., Nestorova, A., and Grossniklaus, U. (2014). A calcium dialog mediated by the FERONIA signal transduction pathway controls plant sperm delivery. Dev. Cell 29, 491-500. doi: 10.1016/j.devcel.2014.04.008

Nguema-Ona, E., Coimbra, S., Vicré-Gibouin, M., Mollet, J.-C., and Driouich, A. (2012). Arabinogalactan proteins in root and pollen-tube cells: distribution and functional aspects. Ann. Bot. 110, 383-404. doi: 10.1093/aob/mcs143

Nodine, M. D., and Bartel, D. P. (2012). Maternal and paternal genomes contribute equally to the transcriptome of early plant embryos. Nature 482, 94-97. doi: 10.1038 /nature 10756

Nowack, M. K., Grini, P. E., Jakoby, M. J., Lafos, M., Koncz, C., and Schnittger, A. (2006). A positive signal from the fertilization of the egg cell sets off endosperm proliferation in angiosperm embryogenesis. Nat. Genet. 38, 63-67. doi: $10.1038 / n g 1694$

Ogawa, M., Kay, P., Wilson, S., and Swain, S. M. (2009). ARABIDOPSIS DEHISCENCE ZONE POLYGALACTURONASE1 (ADPG1), ADPG2, and QUARTET2 are polygalacturonases required for cell separation during reproductive development in Arabidopsis. Plant Cell 21, 216-233. doi: $10.1105 /$ tpc. 108.063768

Okuda, S., Suzuki, T., Kanaoka, M. M., Mori, H., Sasaki, N., and Higashiyama, T. (2013). Acquisition of LURE-binding activity at the pollen tube tip of Torenia fournieri. Mol. Plant 6, 1074-1090. doi: 10.1093/mp/sst050

Okuda, S., Tsutsui, H., Shiina, K., Sprunck, S., Takeuchi, H., Yui, R., et al. (2009). Defensin-like polypeptide LUREs are pollen tube attractants secreted from synergid cells. Nature 458, 357-361. doi: 10.1038/nature07882

Olsen, A. N., Mundy, J., and Skriver, K. (2002). Peptomics, identification of novel cationic Arabidopsis peptides with conserved sequence motifs. In Silico Biol. 2 441-451.

Palanivelu, R., Brass, L., Edlund, A. F., and Preuss, D. (2003). Pollen tube growth and guidance is regulated by $P O P 2$, an Arabidopsis gene that controls GABA levels. Cell 114, 47-59. doi: 10.1016/S0092-8674(03)00479-3

Palanivelu, R., and Preuss, D. (2006). Distinct short-range ovule signals attract or repel Arabidopsis thaliana pollen tubes in vitro. BMC Plant Biol. 6:7. doi: 10.1186/1471-2229-6-7

Palanivelu, R., and Tsukamoto, T. (2012). Pathfinding in angiosperm reproduction: pollen tube guidance by pistils ensures successful double fertilization. Wiley Interdiscip. Rev. Dev. Biol. 1, 96-113. doi: 10.1002/wdev.6

Pearce, G., Moura, D. S., Stratmann, J., and Ryan, C. A. (2001). RALF, a 5-kDa ubiquitous polypeptide in plants, arrests root growth and development. Proc. Natl. Acad. Sci. U.S.A. 98, 12843-12847. doi: 10.1073/pnas.201416998

Punwani, J. A., Rabiger, D. S., Lloyd, A., and Drews, G. N. (2008). The MYB98 subcircuit of the synergid gene regulatory network includes genes directly and indirectly regulated by MYB98. Plant J. 55, 406-414. doi: 10.1111/j.1365313X.2008.03514.x

Punwani, J., Rabiger, D. S., and Drews, G. N. (2007). MYB98 positively regulates a battery of synergid-expressed genes encoding filiform apparatus localized proteins. Plant Cell 19, 2557-2568. doi: 10.1105/tpc.107.052076

Roldán, J. A., Rojas, H. J., and Goldraij, A. (2012). Disorganization of F-actin cytoskeleton precedes vacuolar disruption in pollen tubes during the in vivo self-incompatibility response in Nicotiana alata. Ann. Bot. 110, 787-795. doi: 10.1093/aob/mcs153

Rotman, N., Rozier, F., Boavida, L., Dumas, C., Berger, F., and Faure, J. (2003). Female control of male gamete delivery during fertilization in 
Arabidopsis thaliana. Supplements. Curr. Biol. 13, 432-436. doi: 10.1016/S09609822(03)00093-9

Samuel, M. A., Chong, Y. T., Haasen, K. E., Aldea-Brydges, M. G., Stone, S. L., and Goring, D. R. (2009). Cellular pathways regulating responses to compatible and self-incompatible pollen in Brassica and Arabidopsis stigmas intersect at Exo70A1, a putative component of the exocyst complex. Plant Cell 21, 2655-2671. doi: 10.1105/tpc. 109.069740

Sandaklie-Nikolova, L., Palanivelu, R., King, E. J., Copenhaver, G. P., and Drews, G. N. (2007). Synergid cell death in Arabidopsis is triggered following direct interaction with the pollen tube. Plant Physiol. 144, 1753-1762. doi: 10.1104/pp.107.098236

Schopfer, C. R. (1999). The male determinant of self-incompatibility in Brassica. Science 286, 1697-1700. doi: 10.1126/science.286.5445.1697

Scott, R. J., Armstrong, S. J., Doughty, J., and Spielman, M. (2008). Double fertilization in Arabidopsis thaliana involves a polyspermy block on the egg but not the central cell. Mol. Plant 1, 611-619. doi: 10.1093/mp/ssn016

Shi, Y.-Y., Tao, W.-J., Liang, S.-P., Lü, Y., and Zhang, L. (2009). Analysis of the tipto-base gradient of CaM in pollen tube pulsant growth using in vivo CaM-GFP system. Plant Cell Rep. 28, 1253-1264. doi: 10.1007/s00299-009-0725-z

Shiba, H., Takayama, S., Iwano, M., Shimosato, H., Funato, M., Nakagawa, T., et al. (2001). A pollen coat protein, SP11/SCR, determines the pollen S-specificity in the self-incompatibility of Brassica species. Plant Physiol. 125, 2095-2103. doi: 10.1104/pp.125.4.2095

Shimizu, K. K., Ito, T., Ishiguro, S., and Okada, K. (2008). MAA3 (MAGATAMA3) helicase gene is required for female gametophyte development and pollen tube guidance in Arabidopsis thaliana. Plant Cell Physiol. 49, 1478-1483. doi: $10.1093 / \mathrm{pcp} / \mathrm{pcn} 130$

Shimizu, K. K., and Okada, K. (2000). Attractive and repulsive interactions between female and male gametophytes in Arabidopsis pollen tube guidance. Development 127, 4511-4518. doi: 10.5167/uzh-71801

Sprunck, S., Rademacher, S., Vogler, F., Gheyselinck, J., Grossniklaus, U., and Dresselhaus, T. (2012). Egg cell-secreted EC1 triggers sperm cell activation during double fertilization. Science 338, 1093-1097. doi: 10.1126/science. 1223944

Steele, R. E., and Dana, C. E. (2009). Evolutionary history of the HAP2/GCS1 gene and sexual reproduction in metazoans. PLoS ONE 4:e7680. doi: 10.1371/journal.pone. 0007680

Steinhorst, L., and Kudla, J. (2013a). Calcium - a central regulator of pollen germination and tube growth. Biochim. Biophys. Acta 1833, 1573-1581. doi: 10.1016/j.bbamcr.2012.10.009

Steinhorst, L., and Kudla, J. (2013b). Calcium and reactive oxygen species rule the waves of signaling. Plant Physiol. 163, 471-485. doi: 10.1104/pp.113.222950

Stratford, S., Barne, W., Hohorst, D. L., Sagert, J. G., Cotter, R., Golubiewski, A., et al. (2001). A leucine-rich repeat region is conserved in pollen extensinlike (Pex) proteins in monocots and dicots. Plant Mol. Biol. 46, 43-56. doi: 10.1023/A:1010659425399

Synek, L., Schlager, N., Eliás, M., Quentin, M., Hauser, M., and Zárskı, V. (2006). AtEXO70A1, a member of a family of putative exocyst subunits specifically expanded in land plants, is important for polar growth and plant development. Plant J. 48, 54-72. doi: 10.1111/j.1365-313X.2006.02854.x

Takasaki, T., Hatakeyama, K., Suzuki, G., Watanabe, M., Isogai, A., and Hinata, K. (2000). The $S$ receptor kinase determines self-incompatibility in Brassica stigma. Nature 403, 913-916. doi: 10.1038/35002628

Takeuchi, H., and Higashiyama, T. (2012). A species-specific cluster of defensinlike genes encodes diffusible pollen tube attractants in Arabidopsis. PLoS Biol. 10:e1001449. doi: 10.1371/journal.pbio.1001449
Uebler, S., Dresselhaus, T., and Márton, M.-L. (2013). Species-specific interaction of EA1 with the maize pollen tube apex. Plant Signal. Behav. 8, e25682. doi: 10.4161/psb.25682

Van Ex, F., Jacob, Y., and Martienssen, R. A. (2011). Multiple roles for small RNAs during plant reproduction. Curr. Opin. Plant Biol. 14, 588-593. doi: 10.1016/j.pbi.2011.07.003

Völz, R., Heydlauff, J., Ripper, D., von Lyncker, L., and Groß-Hardt, R. (2013). Ethylene signaling is required for synergid degeneration and the establishment of a pollen tube block. Dev. Cell 25, 310-316. doi: 10.1016/j.devcel.2013.04.001

Watanabe, M., Suwabe, K., and Suzuki, G. (2012). Molecular genetics, physiology and biology of self-incompatibility in Brassicaceae. Proc. Jpn. Acad,. Ser. B,. Phys. Biol. Sci. 88, 519-535. doi: 10.2183/pjab.88.519

Wheeler, M. J., de Graaf, B. H. J., Hadjiosif, N., Perry, R. M., Poulter, N. S., Osman, K., et al. (2009). Identification of the pollen self-incompatibility determinant in Papaver rhoeas. Nature 459, 992-995. doi: 10.1038/nature08027

Willemse, M. T. M., and van Went, J. L., (1984). "The female gametophyte," in Embryology of Angiosperms, ed B. M. Johri (Berlin, Heidelberg: Springer Berlin Heidelberg), 159-196. doi: 10.1007/978-3-642-69302-1_4

Wolters-Arts, M., Lush, W. M., and Mariani, C. (1998). Lipids are required for directional pollen-tube growth. Nature 392, 818-821. doi: 10.1038/33929

Wong, J. L., and Johnson, M. (2010). Is HAP2-GCS1 an ancestral gamete fusogen? Trends Cell Biol. 20, 134-141. doi: 10.1016/j.tcb.2009.12.007

Woriedh, M., Wolf, S., Márton, M. L., Hinze, A., Gahrtz, M., Becker, D., et al. (2013). External application of gametophyte-specific ZmPMEI1 induces pollen tube burst in maize. Plant Reprod. 26, 255-266. doi: 10.1007/s00497-013-0221-z

Wu, H. M., Wang, H., and Cheung, A. Y. (1995). A pollen tube growth stimulatory glycoprotein is deglycosylated by pollen tubes and displays a glycosylation gradient in the flower. Cell 82, 395-403. doi: 10.1016/0092-8674(95)90428-X

Wu, J., Wang, S., Gu, Y., Zhang, S., Publicover, S. J., and Franklin-Tong, V. E. (2011). Self-incompatibility in Papaver rhoeas activates nonspecific cation conductance permeable to $\mathrm{Ca}^{2+}$ and $\mathrm{K}^{+}$. Plant Physiol. 155, 963-973. doi: 10.1104/pp.110.161927

Cheung, A, Y., Wang, H., and Wu, H. M. (1995). A floral transmitting tissue-specific glycoprotein attracts pollen tubes and stimulates their growth. Cell 82, 383-393. doi: 10.1016/0092-8674(95)90427-1

Zhou, L., Fu, Y., and Yang, Z. (2009). A genome-wide functional characterization of Arabidopsis regulatory calcium sensors in pollen tubes. J. Integr. Plant Biol. 51, 751-761. doi: 10.1111/j.1744-7909.2009.00847.x

Conflict of Interest Statement: The authors declare that the research was conducted in the absence of any commercial or financial relationships that could be construed as a potential conflict of interest.

Received: 26 May 2014; accepted: 21 August 2014; published online: 11 September 2014.

Citation: Bleckmann A, Alter S and Dresselhaus T (2014) The beginning of a seed: regulatory mechanisms of double fertilization. Front. Plant Sci. 5:452. doi: 10.3389/ fpls.2014.00452

This article was submitted to Plant Evolution and Development, a section of the journal Frontiers in Plant Science.

Copyright $\odot 2014$ Bleckmann, Alter and Dresselhaus. This is an open-access article distributed under the terms of the Creative Commons Attribution License (CC BY). The use, distribution or reproduction in other forums is permitted, provided the original author(s) or licensor are credited and that the original publication in this journal is cited, in accordance with accepted academic practice. No use, distribution or reproduction is permitted which does not comply with these terms. 